\title{
Adaptation to mild hypoglycaemia in normal subjects despite sustained increases in counter-regulatory hormones
}

\author{
D.Kerr ${ }^{1}$, I.A. Macdonald ${ }^{2}$ and R.B. Tattersall ${ }^{1}$ \\ ${ }^{1}$ Department of Medicine and ${ }^{2}$ Department of Physiology/Pharmacology, University Hospital, Nottingham, UK
}

\begin{abstract}
Summary. In diabetes, loss of awareness of and a defective hormonal response to hypoglycaemia have been associated with long disease duration, improved glycaemic control and possibly a change in insulin species. In contrast it is assumed that normal subjects always have symptoms when their blood glucose is low. We have tested this in 7 normal subjects at 3 levels of blood glucose $(4.5,3.5$ and $3.0 \mathrm{mmol} / 1)$ using a hyperinsulinaemic glucose clamp with a euglycaemic $(4.5 \mathrm{mmol} / \mathrm{l})$ clamp as a control. After $60 \mathrm{~min}$ at a blood glucose of $3.5 \mathrm{mmol} / 1$ adrenaline and glucagon increased slightly but significantly, whereas cortisol, growth hormone and pancreatic polypeptide were unchanged. As soon as glucose was lowered to $3.0 \mathrm{mmol} / 1$ adrenaline increased to $1.10 \mathrm{nmol} / \mathrm{l}$ and rose further to $1.43 \mathrm{nmol} / \mathrm{l}$ after $60 \mathrm{~min}$. Glu-
\end{abstract}

cagon secretion increased similarly but other counter-regulatory hormones were significantly raised only after $60 \mathrm{~min}$ at $3.0 \mathrm{mmol} / \mathrm{l}$. Awareness of hypoglycaemia (symptom score) increased after $40 \mathrm{~min}$ at a blood glucose of $3.0 \mathrm{mmol} / 1$ but after $60 \mathrm{~min}$ decreased to baseline levels with loss of awareness in 5 subjects. Reaction time improved in parallel with the change in symptom score. Thus, despite high levels of adrenaline, normal subjects lose awareness during sustained mild hypoglycaemia. Improved reaction time may reflect cerebral adaptation.

Key words: Counter-regulation, hypoglycaemia, catecholamines, glucagon, hypoglycaemic unawareness.
Hypoglycaemia is the commonest side-effect of insulin treatment but is often unrecognised by the diabetic patient [1]. Loss of awareness in diabetic patients has been attributed to diminished adrenaline secretion [2]. Diminished awareness and attenuation of the hormonal counter-regulatory response occur with increasing duration of diabetes [3], improved glycaemic control [4], and possibly a change in insulin species [5]. In clinical practice it is a common experience that diabetic patients (especially when pregnant) may feel and appear "normal" despite blood glucoses of $2.0 \mathrm{mmol} / 1$ or less. The same is true for patients with insulinomas [6]. We wondered whether this apparent tolerance of frequent low blood glucose concentrations might reflect an adaptive mechanism and, in particular, whether awareness might change during a single episode of hypoglycaemia.

\section{Subjects and methods}

\section{Subjects}

Seven healthy nurses or medical students ( 5 female) with a median age of 23 years (range 22-33) were recruited. All had a body mass index below $26 \mathrm{kgm}^{-2}$. None was taking any medication apart from the oral contraceptive pill (four). Written consent was obtained for the study which was approved by the medical school and hospital ethical committees.

Studies were performed in the afternoon on 2 occasions separated by at least 2 weeks. After a light breakfast subjects fasted until 13.00 hours when under local anaesthetic a cannula was placed in an antecubital vein of the non-dominant arm for infusion of human Actrapid insulin (Novo Laboratories, Copenhagen, Denmark) at a fixed rate of $60 \mathrm{mU} \cdot \mathrm{m}^{2-1} \cdot \mathrm{min}^{-1}$ and a variable infusion of $20 \%$ glucose. A modified hyperinsulinaemic clamp [7] was used to maintain blood glucose at pre-determined levels. Arterialised venous blood samples were obtained from a cannula in a dorsal hand vein of the same arm; the hand was placed in a heated box $\left(55-60^{\circ} \mathrm{C}\right)$ and the cannula kept patent by a $154 \mathrm{mmol} / \mathrm{I} \mathrm{NaCl}$ infusion.

Glucose was administered by an IVAC 560 pump (IVAC, San Diego, CA, USA), adjusted every $2.5 \mathrm{~min}$ according to blood glucose measured at the bedside with a glucose oxidase method (Yellow Springs Instrument, Yellow Springs, Ohio, USA). Subjects were then randomised to have blood glucose maintained at $4.5 \mathrm{mmol} / 1$ for the duration of the experiment $(180 \mathrm{~min})$ or after a period of $30 \mathrm{~min}$ at a blood glucose of $4.5 \mathrm{mmol} / 1$, have it reduced to $3.5 \mathrm{mmol} / 1$ for $60 \mathrm{~min}$ and then $3.0 \mathrm{mmol} / 1$ for a further $60 \mathrm{~min}$. Blood glucose was allowed to fall by varying the glucose infusion rate.

All subjects were informed of the likely symptoms of hypoglycaemia before both experiments. Some had a textbook knowledge of the symptoms but none had ever experienced them before. They knew that blood glucose would be lowered during one or other experiment, but they did not know the level at any stage. 


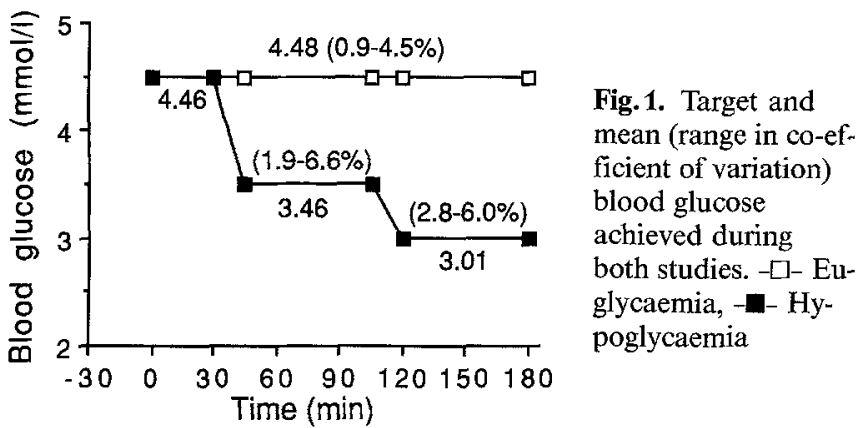

\section{Physiological measurements}

Heart rate and blood-pressure were measured by an automated method (Accutor 1A monitor, Datascope Corp. NJ, USA). Rates of sweating were measured over the lower sternum with a ventilated capsule using dewpoint sensors (Michell Instruments, Cambridge, UK) to estimate the water content of inflowing and outflowing air [8]. Finger tremor was measured by an accelerometer (Bruel and Kjaer 4367 Naerum, Denmark) attatched by a "Perspex" ring to the terminal phalanx of the middle finger of the dominant hand. Measurements were made for periods of $1 \mathrm{~min}$, with the forearm supported and hand outstretched as previously described [9].

Awareness of hypoglycaemia was assessed by asking "do you feel as if your blood glucose is low?" In addition a "hypoglycaemic symptom score' was obtained by asking subjects to rate seven symptoms as absent, mild or moderate or severe (scored $0,1,2$ or 4 respectively). The symptoms were facial flushing, tingling of the fingers or around the mouth, trembling, palpitations, sweating, blurred vision and sleepiness. Dummy questions (not scored) were included to detect individuals who were answering automatically because of neuroglycopaenia. Physiological measurements were made once at a blood glucose of $4.5 \mathrm{mmol} / 1$, three times at $3.5 \mathrm{mmol} / \mathrm{l}$, and three times at $3.0 \mathrm{mmol} / 1$ separated by $20 \mathrm{~min}$ intervals. Measurements were made at the same times during the euglycaemic study.

Reaction time was measured with a single unprepared reaction timer [10] over $10 \mathrm{~min}$ at baseline (blood glucose $4.5 \mathrm{mmol} / \mathrm{l}$ ), twice over ten min intervals with blood glucose at $3.5 \mathrm{mmol} / 1$ and twice at $3.0 \mathrm{mmol} / \mathrm{l}$. During the euglycaemic study reaction time was measured at the same times. Subjects depress a microswitch in response to a flashing light which automatically comes on and off after an unpredictable delay (variable 2 to $12 \mathrm{~s}$ interval). The latency period is recorded on cassette tape for subsequent computer analysis.

\section{Counter-regulatory hormone analysis}

After the reaction time measurements, blood was taken from the heated hand vein, centrifuged at $4^{\circ} \mathrm{C}$ and $3500 \mathrm{rev} / \mathrm{min}$ for $10 \mathrm{~min}$ and the plasma added to tubes containing $75 \mu \mathrm{l}$ of EGTA-glutathione for measurement of catecholamines, $75 \mu \mathrm{l}$ of Trasylol (Bayer UK Ltd, Newbury, Berks, UK) for glucagon and pancreatic polypeptide, and into plain tubes for insulin, growth hormone and cortisol. The tubes were stored at $-80^{\circ} \mathrm{C}$. Adrenaline and noradrenaline were measured by high performance liquid chromatography with electrochemical detection [11]. Cortisol and growth hormone were measured by an inhouse direct radioimmunoassay. Insulin [12], glucagon [13] and pancreatic polypeptide [14] were measured by radioimmunoassay. Intra-assay co-efficients of variation were; glucagon $11.1 \%$, adrenaline $6 \%$, growth hormone $6.8 \%$, and cortisol $6 \%$.

\section{Statistical analysis}

Results are expressed as mean and standard error of the mean. Where appropriate, data were logarithmically transformed before two-way and one-way analysis of variance with Duncans range test were per- formed. When two-way analysis of variance indicated significant treatment by time interactions, the nature of these differences was determined by paired $t$-tests on the contrasts in group means.

\section{Results}

Blood glucose and insulin (Fig. 1)

Blood glucose targets were achieved during both experiments with co-efficients of variation between 0.9 and $6.0 \%$. Plasma insulin levels were $93.4(4.6) \mathrm{mU} / 1$ in the hypoglycaemic study and 99.9 (3.9) $\mathrm{mU} / 1$ in the euglycaemic study and did not vary significantly with time.

\section{Adrenaline and noradrenaline (Fig. 2)}

Basal adrenaline levels were similar; $(0.38(0.06) \mathrm{nmol} / \mathrm{1}$ hypoglycaemic clamp, $0.31(0.05) \mathrm{nmol} / 1$ euglycaemic clamp) and did not change significantly during the euglycaemic clamp. After $60 \mathrm{~min}$ at a blood glucose concentration of $3.5 \mathrm{mmol} / 1$ adrenaline increased significantly to $0.57(0.07) \mathrm{nmol} / 1 \quad(p<0.05)$. When blood glucose was lowered to $3.0 \mathrm{mmol} / 1$ adrenaline increased to $1.10(0.23) \mathrm{nmol} / 1(p<0.01)$ and rose further to $1.43(0.35) \mathrm{nmol} / 1$ after $60 \mathrm{~min}$. There was no significant change in plasma noradrenaline in either study.

\section{Plasma cortisol, pancreatic polypeptide and growth hormone (Fig. 2)}

Basal cortisol levels were similar; $(234(33.4) \mathrm{nmol} / 1$ hypoglycaemic clamp, 291 (30.8) nmol/1 euglycaemic clamp). The normal decrease in cortisol which occurs as the afternoon progresses was lost during the hypoglycaemic study. Cortisol increased significantly from baseline to $417(99.1) \mathrm{nmol} / 1(p<0.05)$ after $60 \mathrm{~min}$ at a blood glucose of $3.0 \mathrm{mmol} / 1$. Basal growth hormone levels were not significantly different (hypoglycaemic clamp $3.34(0.5) \mathrm{mU} / 1$, euglycaemic clamp 7.41 (4.0) $\mathrm{mU} / \mathrm{l}$ ) and did not increase during the euglycaemic clamp. When blood glucose was lowered to $3.0 \mathrm{mmol} / 1$, growth hormone increased promptly to $9.23(3.6) \mathrm{mU} / 1(p<0.05)$ followed by a further rise to $35.5(20.4) \mathrm{mU} / 1(p<0.05)$ after $60 \mathrm{~min}$. Basal pancreatic polypeptide levels were similar; $57.1(6.2)$ in the euglycaemic study and $53.7(13.5) \mathrm{ng} / 1$ in the hypoglycaemic study. After $60 \mathrm{~min}$ at a blood glucose of $3.0 \mathrm{mmol} / 1$, pancreatic polypeptide increased to $177.9(81.7) \mathrm{ng} / 1(p<0.05)$.

\section{Plasma glucagon}

Basal levels were similar for both studies (129.3 (6.2) euglycaemic clamp and $128.6(3.7) \mathrm{ng} / 1$ hypoglycaemic study) and did not change during the euglycaemic 

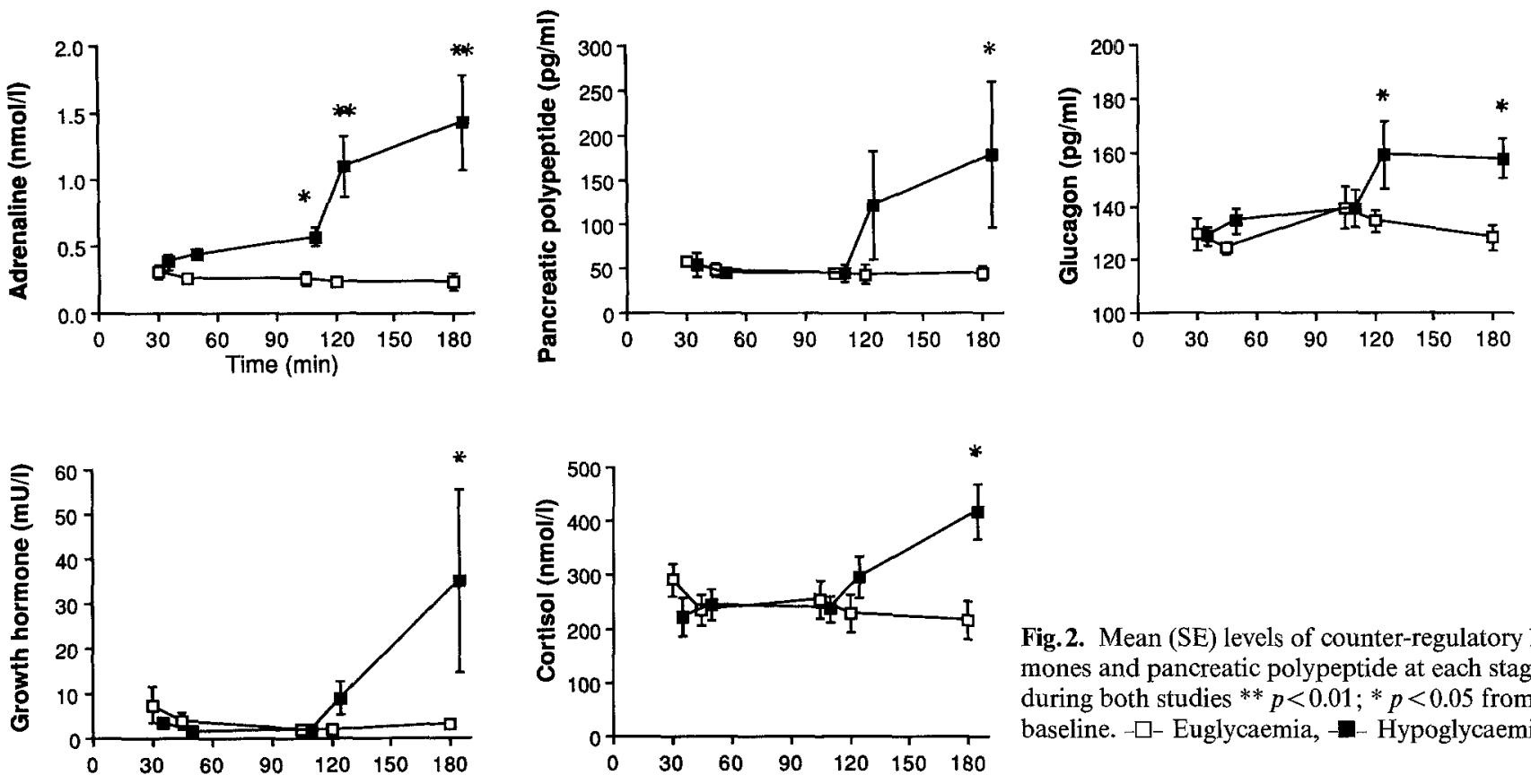

Fig. 2. Mean (SE) levels of counter-regulatory hormones and pancreatic polypeptide at each stage during both studies ** $p<0.01 ; * p<0.05$ from baseline. $-\square$ - Euglycaemia, - - Hypoglycaemia clamp or at a blood glucose of $3.5 \mathrm{mmol} / 1$ during the hypoglycaemic clamp. On lowering blood glucose to $3.0 \mathrm{mmol} / 1$, glucagon increased to $159.3(12.4) \mathrm{ng} / 1$ $(p<0.05)$ and remained elevated after $60 \mathrm{~min}$ compared to baseline (157.9 (7.3) ng/l) and to euglycaemic clamp.

\section{Physiological measurements (Fig. 3)}

During the euglycaemic clamp there were no significant changes. During the hypoglycaemic clamp heart rate, systolic blood-pressure and sweating did not change significantly. Tremor amplitude (root mean square acceleration over the $0-50 \mathrm{~Hz}$ frequency spectrum) was similar at baseline during the euglycaemic $\left(0.199(0.38) \mathrm{ms}^{-2}\right)$ and hypoglycaemic $(0.192$ $\left.(0.038) \mathrm{ms}^{-2}\right)$ studies and did not change when blood glucose was lowered to $3.5 \mathrm{mmol} / \mathrm{l}$. However, as soon as blood glucose was lowered to $3.0 \mathrm{mmol} / 1$, tremor increased significantly $\left(+0.12(0.03) \mathrm{ms}^{-2}, p<0.05\right)$ and this was maintained over $60 \mathrm{~min}(+0.18$ $\left.(0.09) \mathrm{m} \mathrm{s}^{-2}\right)$. Diastolic blood-pressure fell by $5 \mathrm{~mm} \mathrm{Hg}$ initially on lowering the blood glucose to $3.0 \mathrm{mmol} / 1$ $(p<0.05)$ and remained at this level.

\section{Awareness of hypoglycaemia}

There was no change in symptom score during the euglycaemic study. During the hypoglycaemia study, after $40 \mathrm{~min}$ at a blood glucose of $3.0 \mathrm{mmol} / 1$, symptom score increased $(0.4(0.2)$ baseline vs $2.4(0.7) p<0.02)$, mainly due to increased reporting of blurred vision, trembling and sleepiness. However, by $60 \mathrm{~min}$ the score had decreased to $0.7(0.3)(p<0.05)$ (Table 1). After $40 \mathrm{~min}$ at a blood glucose concentration of $3.0 \mathrm{mmol} / 1$ 5 subjects said they "felt" hypoglycaemic but none were aware of hypoglycaemia after $60 \mathrm{~min}$. Similarly reaction time slowed during the hypoglycaemic clamp from a mean baseline of $278.7(20.4) \mathrm{ms}$ to $349.1(43.6) \mathrm{ms}$ $p<0.05$ when blood glucose was lowered to $3.0 \mathrm{mmol} / 1$. After $60 \mathrm{~min}$ at $3.0 \mathrm{mmol} / 1$, reaction time improved (in parallel with the symptom score) to 287.0 (22.5) ms (Fig.4).

\section{Discussion}

In this study, after $40 \mathrm{~min}$ at a blood glucose of $3.0 \mathrm{mmol} / 1,5$ subjects "felt hypoglycaemic". This was associated with an increase in symptom score, both adrenergic (trembling) and neuroglycopaenic (sleepiness, blurred vision) symptoms and a deterioration in reaction time. Prolonging the duration of this level of hypoglycaemia caused a decrease in symptom score and all subjects lost their awareness of being hypoglycaemic. This was paralleled by improved reaction time.

In practical terms, hypoglycaemia is usually recognised by the symptom complexes produced. These have traditionally been divided into those attributable to adrenaline release, and those due to neuroglycopaenia [15]. The role of adrenaline in causing symptoms is often overstated and symptoms in adrenalectomised patients are similar to those described by patients with intact adrenals [16]. The extent to which other symptoms are the result of adrenomedullary adrenaline secretion or sympathetic nerve noradrenaline is not clear, but there is some experimental support for the latter [17, $18]$. 

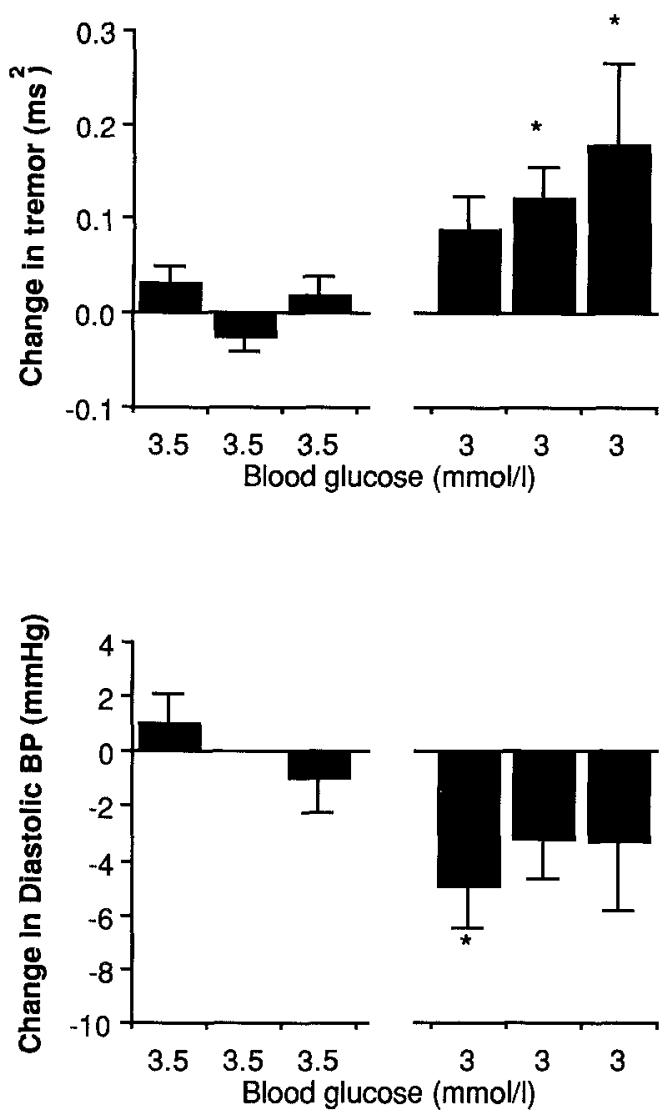

Fig.3. Sequential measurements over time of the change in tremor and diastolic blood-pressure (BP) from baseline (blood glucose $4.5 \mathrm{mmol} / 1$ ) during the hypoglycaemic study. $* p<0.05$. Values did not change significantly during the euglycaemic study

Table 1. Symptom scores for the 7 subjects during the hypoglycaemia study

\begin{tabular}{|c|c|c|c|c|c|c|c|}
\hline \multirow[t]{2}{*}{ Symptoms } & \multicolumn{7}{|c|}{ Blood glucose $(\mathrm{mmol} / \mathrm{l})$} \\
\hline & 4.5 & $\begin{array}{l}3.5 \\
(20 \mathrm{~min})\end{array}$ & $\begin{array}{l}3.5 \\
(40 \mathrm{~min}\end{array}$ & $\begin{array}{l}3.5 \\
(60 \mathrm{~min})\end{array}$ & $\begin{array}{l}3.0 \\
(20 \mathrm{~min})\end{array}$ & $\begin{array}{l}3.0 \\
(40 \mathrm{~min})\end{array}$ & $\begin{array}{l}3.0 \\
(60 \mathrm{~min})\end{array}$ \\
\hline Sweating & 1 & 0 & 0 & 1 & 0 & 2 & 1 \\
\hline $\begin{array}{l}\text { Blurred } \\
\text { vision }\end{array}$ & 0 & 0 & 1 & 1 & 0 & 4 & 0 \\
\hline Tingling & 0 & 0 & 1 & 1 & 1 & 1 & 0 \\
\hline Trembling & 0 & 0 & 1 & 0 & 1 & 3 & 2 \\
\hline $\begin{array}{l}\text { Pal- } \\
\text { pitations }\end{array}$ & 0 & 0 & 0 & 0 & 0 & 0 & 0 \\
\hline Sleepiness & 1 & 2 & 2 & 2 & 3 & 5 & 1 \\
\hline $\begin{array}{l}\text { Facial } \\
\text { flushing }\end{array}$ & 1 & 0 & 1 & 1 & 0 & 2 & 1 \\
\hline
\end{tabular}

Others have also shown dissociation between what the patients feels, and the hormonal counter-regulatory response [19]. Schwartz et al. have clarified this using the hyperinsulinaemic glucose clamp to produce predetermined, stepped reductions in blood glucose in healthy volunteers [20]. They found a hierarchy for release of counter-regulatory hormones with adrenaline being released at higher levels of blood glucose $(3.8 \mathrm{mmol} / 1)$ than cortisol $(3.0 \mathrm{mmol} / 1)$. Schwartz et al.
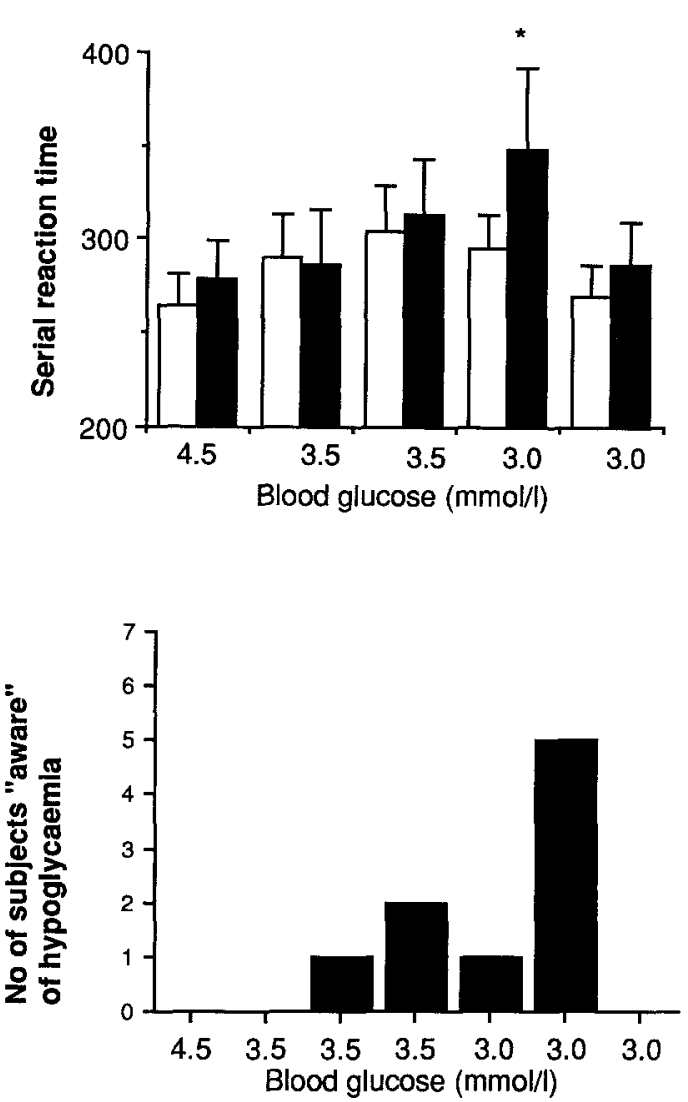

Fig.4. Sequential ${ }_{4}$ measurements (mean $[\mathrm{SE}]$ ) of serial reaction time (milliseconds), and number of subjects aware of hypoglycaemia at each level of blood glucose. $\square$ Euglycaemia, $\square$ Hypoglycaemia, $* p<0.05$ compared to baseline

used a more complex symptom questionnaire than ours in which 12 symptoms (none dummy) were scored from $0-10$. They found that the mean symptom score began to increase when blood glucose was lowered from 3.8 to $3.3 \mathrm{mmol} / 1$ and clearly exceeded control values in the step in which blood glucose was lowered from 3.3 to $2.7 \mathrm{mmol} / 1$. In their study, the symptom questionnaire was administered 6 times an hour at each hypoglycaemic level, and appeared to increase progressively and exactly in parallel with the rise in adrenaline.

It is a common clinical experience that some patients do not reliably or consistently recognise hypoglycaemia. In a previous study in patients with diabetes we showed that at a blood glucose of $2.5 \mathrm{mmol} / 1$ unawareness was associated with a decreased adrenaline response [21]. One explanation for hypoglycaemic unawareness in patients with diabetes is that the threshold for release of adrenaline is reset at a lower blood glucose concentration following sustained improvement in diabetic control $[4,22]$. Here, we have shown that prolonging mild hypoglycaemia in normal subjects results in loss of awareness despite high circulating levels of adrenaline and sustained increases in other counterregulatory hormones. Loss of awareness did not appear to be due to cerebral dysfunction since reaction time improved in parallel with loss of symptoms. Tolerance to 
the effects of adrenaline has been suggested by some workers [23] as an explanation for reduced awareness, but is unlikely in the present study as finger tremor (mediated by forearm beta-adrenergic receptors [24]) increased progressively in parallel with adrenaline levels. The improvement in reaction time suggests cerebral adaptation either because the brain uses alternative fuels or because cerebral glucose availability is increased. After prolonged fasting, when plasma insulin levels fall to very low levels, alternative cerebral fuels can be used as an energy source in place of glucose [25]. Drenick et al. [26] performed insulin tolerance tests, in obese humans before and after prolonged fasting. Fasting resulted in loss of hypoglycaemic symptoms despite a lower and more prolonged nadir of blood glucose ( $2.11 \mathrm{vs} 2.94 \mathrm{mmol} / \mathrm{l}$ ) and there was augmented cerebral uptake of $\beta$-hydroxybutyrate during hypoglycaemia in the fasted state. Experimental studies in animals have shown that ketone body infusion inhibits the catecholamine response to hypoglycaemia [27] although this has not been confirmed in man [28]. However, the present study was undertaken after a fast of $6 \mathrm{~h}$ only, and it is highly likely that the level of hyperinsulinaemia achieved during the experiment would have suppressed plasma ketone levels [29]. Thus, it is unlikely that the improvement in reaction time and symptom score seen in the present study were due to cerebral utilisation of ketone bodies.

Another explanation for the improvement in reaction time in our subjects could be that glucose delivery to the brain was increased either by increased cerebral blood flow [30] or by increased activity of the glucose transporter. Glucose transport across the blood brain barrier is saturable, i.e. proportional extraction of glucose decreases when plasma glucose concentration increases [31], but increases during chronic mild hypoglycaemia in rats [32]. It has also been argued that hyperinsulinaemia augments cerebral glucose transport $[33,34]$ although this has been disputed [32]. Adrenaline enhances glycolysis in peripheral tissues by stimulating glycogenolysis and gluconeogenesis. However, it is unlikely to have such an effect on the brain as intracerebral gluconeogenesis is negligible and there is insufficient glycogen to supplement glucose availability if hypoglycaemia is prolonged for more than a few minutes [35]. Studies in rats have shown that after a 50\% reduction in plasma glucose concentration, glucose substrate availability becomes the rate limiting step for glycolysis in the brain [36].

At a blood glucose of $3.0 \mathrm{mmol} / 1$ we observed significant increases in counter-regulatory hormones in association with physiological changes and subjective awareness. Prolonging the duration of hypoglycaemia resulted in a decrease in symptom score and awareness, with improved reaction time despite persistence of the physiological changes and increased levels of counterregulatory hormones. These results suggest that cerebral adaptation can occur during prolonged, mild hypo- glycaemia producing dissociation of hypoglycaemic symptoms from the adrenomedullary response.

Acknowledgements. We would like to thank Professor K. D. Buchanan for measuring plasma glucagon and pancreatic polypeptide, $\mathrm{Mr}$. C.Selby of the City Hospital, Nottingham for measuring insulin, growth hormone and cortisol, Dr. M. Herbert for measurement of reaction time and Mr. P. Riley for his statistical guidance. We are indebted to Ms. P. Lister for her help in preparing the manuscript.

\section{References}

1. Balodimos MS, Root HF (1959) Hypoglycemic insulin reactions without warning symptoms. JAMA 171: 261-266

2. White NH, Skor DA, Cryer PE, Levandoski LA, Bier DM, Santiago JV (1983) Identification of type 1 patients at increased risk for hypoglycemia during intensive therapy. $\mathrm{N}$ Eng $\mathrm{J}$ Med 308: 485-491

3. Bolli G, De Feo P, Compagnucci P, Cartechini MG, Angeletti G, Santeusanio F, Brunetti P, Gerich JE (1983) Abnormal glucose counter-regulation in insulin-dependent diabetes mellitus: interaction of anti-insulin antibodies and impaired glucagon and epinephrine secretion. Diabetes 32: 134-141

4. Amiel SA, Tamborlane WB, Simonson DC, Sherwin RS (1987) Defective glucose counter-regulation after strict glycemic control of insulin-dependent diabetes mellitus. N Eng $J$ Med 316: 1376-1383

5. Teuscher A, Berger WG (1987) Hypoglycaemic unawareness in diabetics transferred from beef/porcine insulin to human insulin. Lancet 2: 382-385

6. Scully RE, Mark EJ, McNeely WF, McNeely BU (1988) Case records of the Massachusetts General Hospital: Case 23-1988. N Engl J Med 318: 1523-1532

7. DeFronzo RA, Tobin JD, Andres R (1979) Glucose clamp technique: a method for quantifying insulin secretion and resistance. Am J Physiol 237: E214-223

8. Wilcox RG, Bennett T, Macdonald IA, Herbert M, Skene AM (1984) The effects of acute or chronic ingestion of propranolol or metoprolol on the physiological responses to prolonged submaximal exercise in hypertensive men. Br J Clin Pharm 17: 273-281

9. Birmingham AT, Wharrad HJ, Williams EJ, Wilson CG (1985) Accelerometric measurements of finger tremor; analysis of the analogue signal. J Physiol (London) 361: 12P

10. Millar K, Wilkinson RT (1981) The effects upon vigilance and reaction speed of the addition of ephedrine hydrochloride to chlorpheniramine maleate. Eur J Clin Pharm 20:351-357

11. Macdonald IA, Lake DM (1985) An improved technique for extracting catecholamines from body fluids. J Neuroscience Meth 13: $239-240$

12. Hales CN, Randle PJ (1963) Immunoassay of insulin. Biochem J 88: $137-146$

13. Stout RW, Henry RW, Buchanan KD (1976) Triglyceride metabolism in acute starvation: the role of secretin and glucagon. Eur J Clin Invest 6: 179-185

14. O'Hare MMT, Daly JG, Buchanan KD (1983) Radioimmunoassay for pancreatic polypeptide, and its age-related changes in concentration. Clin Chem 29: 1923-1927

15. Maddocks RK, Krall LP (1953) Insulin reactions: manifestations and need for recognition of long acting insulin reactions. Arch Int Med 91: 695-703

16. Altorfer RM, Zeigler WH, Froesch ER (1981) Insulin hypoglycaemia in normal and adrenalectomised subjects: comparison of metabolic parameters and endocrine counter-regulation. Acta Endocrinol 98: 413-419

17. French EB, Kilpatrick LR (1955) The role of adrenaline in hypoglycaemic reactions in man. Clin Sci 14: 639-665

18. Fagius J, Niklasson F, Berne C (1986) Sympathetic outflow in human muscle nerves increases during hypoglycemia. Diabetes 35: 1124-1129 
19. Ipp E, Forster B (1987) Sparing of cognitive function in mild hypoglycemia: dissociation from the neuroendocrine response. $\mathbf{J}$ Clin Endocrinol Metab 65: 806-810

20. Schwartz NS, Clutter WE, Shah SD, Cryer PE (1987) Glycemic thresholds for activation of glucose counter-regulatory systems are higher than the threshold for symptoms. J Clin Invest 79: 777-781

21. Heller SR, Macdonald IA, Herbert M, Tattersall RB (1987) Influence of sympathetic nervous system on hypoglycaemic warning symptoms. Lancet 2: 359-363

22. Simonson DC, Tamborlane WV, DeFronzo RA, Sherwin RS (1985) Intensive insulin therapy reduces counter-regulatory hormone responses to hypoglycemia in patients with type 1 diabetes. Ann Int Med 103: 184-190

23. Berlin I, Grimaldi A, Payan C, Sachon C, Bosquet F, Thervet F, Puech AJ (1987) Hypoglycemic symptoms and decreased beta adrenergic sensitivity in insulin-dependent diabetic patients. Diabetes Care 10: 742-747

24. Marsden CD, Foley TH, Owen DAL, McAllister RG (1967) Peripheral beta adrenergic receptors concerned with tremor. Clin Sci 33: $53-65$

25. Owen OE, Morgan AP, Kemp HG, Sullivan JM, Herrera MG, Cahill GF (1968) Brain metabolism during fasting. J Clin Invest 46: 1589-1595

26. Drenick EJ, Alvarez LC, Tamasi GC, Brickman AS (1972) Resistance to symptomatic insulin reactions after fasting. J Clin Invest 51: 2757-2762

27. Stricker EM, Rowland N, Saller CF (1977) Homeostasis during hypoglycemia. Central control of epinephrine secretion and peripheral control of feeding. Science 196:79-81

28. Froland L, Kehlet H, Christensen NJ, Alberti KGMM (1980) Effect of ketone body infusion on plasma catecholamine concentrations during acute hypoglycemia in man. J Clin Endocrinol Metab 50: $557-559$
29. Heller SR, Macdonald IA, Tattersall RB (1987) Counterregulation in Type 2 (non-insulin-dependent) diabetes mellitus. Normal endocrine and glycaemic responses, up to ten years after diagnosis. Diabetologia 30: 924-929

30. Neil HAW, Gale EAM, Hamilton SJC, Lopez-Espinoza I, Kaura $R$, McCarthy ST (1987) Cerebral blood flow increases during insulin-induced hypoglycaemia in Type 1 (insulin-dependent) diabetic patients and control subjects. Diabetologia 30:305-309

31. Crone C (1965) Facilitated transfer of glucose from blood into brain tissue. J Physiol (London) 181: 103-113

32. McCall AL, Fixman LB, Fleming N, Tornheim K, Chick W, Ruderman NB (1986) Chronic hypoglycemia increases brain glu* cose transport. Am J Physiol 251: E442-447

33. Amir S, Shecter Y (1987) Centrally mediated hypoglycaemic effect of insulin: apparent involvement of specific insulin receptors. Brain Res 618: 152-156

34. Hertz MM, Paulson DB, Barry DI, Christensen JS, Svendsen PA (1981) Insulin increases glucose transfer across the blood brain barrier in man. J Clin Invest 67: 397-604

35. Bachelard H (1981) Cerebral metabolism and hypoglycaemia. In: Marks V (ed) Hypoglycaemia; Blackwell, Oxford, pp 51-68

36. Robinson PJ, Rapaport SI (1986) Glucose transport and metabolism in the brain. Am J Physiol 250: R127-R136

Received: 26 October 1988

and in revised form: 16 February 1989

Dr. David Kerr

Department of Medicine (Diabetes)

C Floor, South Block

University Hospital

Nottingham NG27 2UH

UK 